\title{
On the retreat of near-Earth neutral line during substorm expansion phase: a THEMIS case study during the 9 January 2008 substorm
}

\author{
X. Cao ${ }^{1}$, Z. Y. Pu ${ }^{2}$, A. M. Du ${ }^{1}$, V. M. Mishin ${ }^{3}$, X. G. Wang ${ }^{4}$, C. J. Xiao ${ }^{4}$, T. L. Zhang ${ }^{5,6}$, V. Angelopoulos ${ }^{7}$, \\ J. P. McFadden ${ }^{8}$, and K. H. Glassmeier ${ }^{9,10}$ \\ ${ }^{1}$ Institute of Geology and Geophysics, Chinese Academy of Sciences, Beijing, China \\ ${ }^{2}$ School of Earth and Space Sciences, Peking University, Beijing, China \\ ${ }^{3}$ Institute of Solar-Terrestrial Physics, Russian Academy of Sciences, Irkusk, Russia \\ ${ }^{4}$ School of Physics, Peking University, Beijing, China \\ ${ }^{5}$ Department of Geophysics and Planetary Sciences, USTC, Hefei, China \\ ${ }^{6}$ Space Research Institute, Austrian Academy of Sciences, Graz, Austria \\ ${ }^{7}$ Department of Earth and Space Sciences and Institute of Geophysics and Planetary Physics, University of California, \\ Los Angeles, CA, USA \\ ${ }^{8}$ Space Sciences Laboratory, University of California, Berkeley, CA, USA \\ ${ }^{9}$ TUBS, 38106 Braunschweig, Germany \\ ${ }^{10}$ Max-Planck-Institut für Sonnensystemforschung, Katlenburg-Lindau, Germany \\ Correspondence to: X. Cao (cx_octor@pku.edu.cn)
}

Received: 23 August 2011 - Revised: 2 December 2011 - Accepted: 5 December 2011 - Published: 16 January 2012

\begin{abstract}
The location of magnetic reconnection in the midtail during a substorm was studied in many researches. Here we present multi-point THEMIS observations of a reconnection event in the near-Earth magnetotail during substorm. In this event, THEMIS probes stayed in the near-Earth and midtail region aligning along the magnetotail. This allows reconnection evolution to be probed simultaneously from about $-10 R_{\mathrm{E}}$ to $-23 R_{\mathrm{E}}$ down tail. The Hall current related electron streams were observed at the same time by two probes far away from the reconnection site. Before near-Earth reconnection involved the tail lobe magnetic field, the reconnection site was restricted in earthward $-23 R_{\mathrm{E}}$. When reconnection involved into the tail lobe region, the reconnection site started to retreat gradually.
\end{abstract}

Keywords. Magnetospheric physics (Magnetotail; Storms and substorms) - Space plasma physics (Magnetic reconnection)

\section{Introduction}

Magnetic reconnection is a physical process which not only produces a change in magnetic field topology, but also converts magnetic field energy into particle kinetic and thermal energies. Magnetic reconnection plays an essential role in various aspects of the formation and dynamics of the Earth's magnetosphere (e.g. Dungey, 1961), especially in substorm physics. Near-Earth neutral line (NENL) model of substorm (McPherron et al., 1973; Baker et al., 1996) is the most principal candidate to interpret the substorm evolution. In the NENL model, a neutral line is formed and the magnetic reconnection occurs in association with a substorm. This causes the formations of the tailward moving plasmoids and the earthward bursty bulk flows (BBFs) which transport magnetic flux, mass and energy at a high speed.

The location of the X-line in the magnetotail is crucial for understanding the substorm process and mechanism. One way to determine the location of the reconnection is the statistical study of the spatial distribution of fast earthward and tailward convection flows, which tend to be accompanied by northward and southward $B_{\mathrm{Z}}$ components, respectively. The study of Geotail data by Nagai et al. (1998a) shows that magnetic reconnections during substorm onsets most frequently take place on the dusk side of the magnetotail at radial distances of $20-30 R_{\mathrm{E}}$. Subsequent studies (e.g. Nagai and Machida, 1998; Baumjohann et al., 1999) have also concluded that magnetic reconnection occurs mostly beyond $20 R_{\mathrm{E}}$ for substorm onsets (Nagai, 2005). This result is consistent with those obtained from the spacecraft

Published by Copernicus Publications on behalf of the European Geosciences Union. 


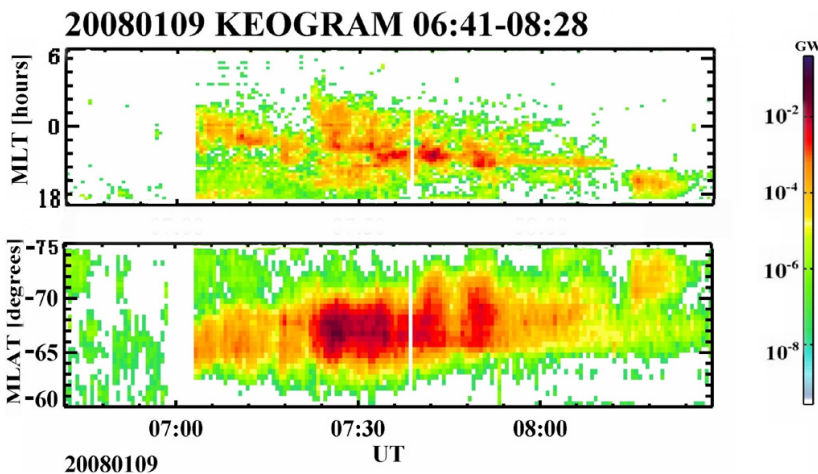

Fig. 1. POLAR UVI keograms during 06:41 UT to 08:28 UT on 9 January 2008: the first breakup occurred during the interval of the data gap from 06:59 UT to 07:02 UT around mid-night. The second breakup appeared at about 07:22 UT at 01:00 MLT.

ISEE 1, ISEE 2 and AMPTE/IRM (e.g. Cattell and Mozer, 1984; Baumjohann et al., 1988, 1989, 1990, 1991). Recently, Miyashita et al. (2009) statistically analysed the plasma flow and magnetic field in the magnetotail related to substorms and found that the magnetic reconnection first occurs in the pre-midnight tail, on average, at $X \sim-16$ to $-20 R_{\mathrm{E}}$ before auroral onset. Then the plasmoid substantially evolves tailward of $X \sim-20 R_{\mathrm{E}}$ immediately after onset. Further study showed that the location of the reconnection is highly dependent on the solar wind condition (Nagai et al., 2005; Nagai, 2006). The $X$-line is closer to the Earth under strong solar wind conditions, and it tends to be located closer to the Earth in more intense substorms (Miyashita et al., 2004). With the Vela satellite's exploration, Hones et al. (1973) concluded that the magnetic reconnection starts near $X \sim$ $-17 R_{\mathrm{E}}$. In some cases the magnetic reconnection can occur at $X \sim-13 R_{\mathrm{E}}$ (Baker et al., 1996). Recently, Miyashita et al. (2005) also reported that the magnetic reconnection occurred earthward of $X \sim-8.6 R_{\mathrm{E}}$, associated with very intense substorms during the 30 October 2003 superstorm. In addition, many magnetic reconnection events were observed inside $-19 R_{\mathrm{E}}$ by Cluster, whose apogee is at $X \sim-19 R_{\mathrm{E}}$ (e.g. Baker et al., 2002; Runov et al., 2003a, b; Slavin et al., 2005; Wang et al., 2010a, b). Du et al. (2011a) also observed reconnection related fast tailward flows inside $-17.6 R_{\mathrm{E}}$ by using THEMIS data.

Another important detectable signature of magnetic reconnection is the Hall current electrons. It has been suggested that along the lobe/plasma sheet boundary one can observe the outer portion of the current loop in the form of lowenergy field-aligned electrons flowing toward the diffusion region along the 4 separatrices (e.g. Fujimoto et al., 1997, 2001; Hoshino et al., 2001; Nagai et al., 2001; Øieroset et al., 2001; Owen et al., 2005; Alexeev et al., 2005; Wang et al., 2010a). On the same field lines, higher energy electrons have also been reported to be directed away from the diffusion region (Hoshino et al., 2001; Nagai et al., 2001; Wang et al., 2010a). Such a configuration has also been confirmed by Lu et al. (2010) who showed that the electron density depletions formed along the separatrices are outside the peaks of the out-of-plane magnetic field.

The magnetic reconnection site does not remain at the same place. It retreats tailward in the late expansion or recovery phase of the substorm (Forbes et al., 1981; Angelopoulos et al., 1996), as predicted by the near-Earth neutral line (NENL) model (Hones, 1976). Hence, the magnetic reconnections and resultant plasmoids can be observed more frequently at larger distances down the tail (Ieda et al., 1998; Ueno et al., 1999). Nagata et al. (2006) also studied the tailward retreat of the reconnection site and estimated the retreat speed at about $250 \mathrm{~km} \mathrm{~s}^{-1}$.

Here, we present a THEMIS observation of retreat of magnetic reconnection in the magnetotail from inside $-16 R_{\mathrm{E}}$ to outside $-23 R_{\mathrm{E}}$ during a substorm expansion phase. In Sect. 2, we give coordinated observations of magnetic reconnection made by two satellites in the mid-tail, along with substorm phenomena in the ionosphere and interplanetary magnetic field information. In Sect. 3, we discuss in detail the phenomena observed and the possible underlying physics. Section 4 is a brief summary.

\section{Observations}

In this paper, we used THEMIS data from the Fluxgate Magnetometer (FGM) instrument (Auster et al., 2008), Solid State Telescope (SST) instrument which measures 25$50 \mathrm{keV}$ particles and Electro-Static Analyser (ESA) instrument (McFadden et al., 2008) which measures $0 \sim 25 \mathrm{keV}$ particles on the THEMIS probes. Magnetic field measurements from 109 ground-based stations at magnetic latitudes higher than $40^{\circ}$ were used to estimate the polar cap magnetic flux, psi, by employing the MIT2 technique (Mishin et al., 2001). Global imaging of the auroral behaviour was made by the Polar UVI instrument (Torr et al., 1995). The THEMIS $\mathrm{AL}$ index was used to indicate the electro jet in the high latitude ionosphere (Angelopoulos et al., 2008). The THEMIS AL index was calculated from THEMIS ground-based observatories at high latitude. From 06:30 UT to 08:30 UT, most of these ground-based observatories were located in the night side. The THEMIS AL index could be a better agency of auroral electro jet (Wang et al., 2009). In addition, OMNI data were used to provide the interplanetary magnetic field (IMF) information.

POLAR UVI observed a substorm aurora breakup at about 07:02 UT followed by an expansion onset at $\sim 07: 22$ UT on 9 January 2008. Figure 1 shows POLAR UVI keograms from 06:41 UT to 08:28 UT. The upper panel is aurora intensity variation (integrated from $-60^{\circ}$ to $-75^{\circ}$ MLAT) along with universal time (UT) at different magnetic local time (MLT) in the night side, and the lower panel is aurora intensity change (integrated from 18:00 MLT to 06:00 MLT) with UT 
and magnetic latitude (MLAT). Before 06:59 UT, there was no aurora activity, but it appeared after 07:02 UT. The intense aurora extended from $-63^{\circ}$ MLAT to $-68^{\circ}$ MLAT at the beginning and then expanded both equatorward and poleward. Although there is a data gap between 06:59 UT and 07:02 UT, the aurora might breakup during the interval of the data gap (at 07:02 UT, the magnetic field started to fluctuate with transient earthward flow in the near-Earth magneto-tail at P3, which confirm that the first onset took place at about 07:02 UT), which travelled westward and slightly poleward. At about 07:22 UT, another breakup appeared at 01:00 MLT. The second breakup was followed by globally aurora poleward/equatorward expansion along with westward travelling of the aurora bulge. The substorm aurora extended poleward to $-75^{\circ}$ MLAT at $\sim 07: 39 \mathrm{UT}$ and after $\sim 07: 50$ UT the aurora faded gradually.

Figure 2 shows OMNI data, the THEMIS AL index, polar cap open magnetic field flux data and THEMIS observations during the interval of 06:30 08:30 UT on 9 January 2008. The IMF $B_{\mathrm{Z}}$ component (Fig. 2a) varied slightly between $-2.5 \mathrm{nT}$ and $-0.5 \mathrm{nT}$, and turned northward at 07:20 UT as indicated by the red dashed vertical line in Fig. 2. The solar wind speed was $\sim 560 \mathrm{~km} \mathrm{~s}^{-1}$ (not shown in this paper). From 06:59 UT, the THEMIS AL index started to decrease quickly from $40 \mathrm{nT}$ to $-350 \mathrm{nT}$ (Fig. 2b). At 07:20 UT, just the time when IMF turned northward, the polar cap open magnetic field flux, psi, dropped sharply from $7.0 \times 10^{8} \mathrm{~Wb}$ to $3.2 \times 10^{8} \mathrm{~Wb}$, which can be seen from Fig. 2c. During the recovery phase of the substorm after 07:50 UT, the psi slowly decreased with small amplitude fluctuations.

During the interval of 06:30 08:30 UT, THEMIS P3, $\mathrm{P} 2$ and $\mathrm{P} 1$ were located in the post-midnight sector along the magnetotail at $[-9.8,-5.2,-3.7] R_{\mathrm{E}},[-16.5,-5.1$, $-5.9] R_{\mathrm{E}}$ and $[-23.3,-5.0,-8.4] R_{\mathrm{E}}$ in Geomagnetic Solar Magnetospheric (GSM) coordinate system, respectively. Throughout the paper, we use the GSM coordinate system for all the THEMIS data. The magnetic field $B_{\mathrm{Z}}$ component from THC (P2) fluctuated within $\pm 2 \mathrm{nT}$ before 07:20 UT, whereas $B_{\mathrm{Z}}$ from THB (P1) always kept negative $(\sim-2 \mathrm{nT})$. At 07:20 UT the $B_{\mathrm{Z}}$ component from both P2 and P1 simultaneously decreased (in Fig. 2d and 2e) and the psi also started to drop. This indicates that the tail lobe reconnection took place somewhere earthward of these two probes, i.e. inside 16.5 $R_{\mathrm{E}}$ (Cao et al., 2008). From 07:20 UT, the total pressure (in Fig. 2f) from P2 and P1 started to decrease slowly while from P3 it began increasing from about $0.3 \mathrm{nPa}$ to $0.4 \mathrm{nPa}$. The decrease in total pressure at $\mathrm{P} 2$ lasted for $\sim 9 \mathrm{~min}$ from $0.13 \mathrm{nPa}$ to $0.07 \mathrm{nPa}$. After 07:29 UT (marked by the cyan vertical dashed line), when $\mathrm{P} 2$ entered into the earthward side of the outflow region of reconnection site, the total pressure kept almost constant until 08:08 UT. Meanwhile, the total pressure at $\mathrm{P} 1$, which was located about $7 R_{\mathrm{E}}$ down tail to P2, was still decreasing. After 07:47 UT (indicated by the black vertical dashed line), when P1 entered into earthward side of the outflow region as well, the total pressure at P1 location reached its minimum value of $0.05 \mathrm{nPa}$ and started to increase slowly. It is worth pointing out that P1 observed northward turning of $B_{\mathrm{Z}}$ at $\sim 07: 43 \mathrm{UT}$, which indicated that P1 was already at the earthward side of reconnection X-line. At that time, P1 was still in the inflow region. At $\sim 07: 47 \mathrm{UT}$, P1 observed earthward flow and met with reconnection separatrices (see Fig. 4 for detail) and then entered into the earthward side outflow region of the reconnection site.

Figure 3 shows detailed observations from probe $\mathrm{P} 2$ at $X \sim-16.5 R_{\mathrm{E}}$ with the same time period as Fig. 2. From top to bottom in Fig. 3a is the ion spectra with an energy range from $10 \mathrm{eV}$ to $50 \mathrm{keV}$, the magnetic field and the ion bulk velocity. Figure $3 \mathrm{~b}$ and $\mathrm{c}$ gives the energy flux spectra of electrons along $\left(0^{\circ}\right)$, opposite $\left(180^{\circ}\right)$ and perpendicular $\left(90^{\circ}\right)$ to the magnetic field for the times marked by the cyan vertical dashed lines in Fig. 3a. Before substorm onset (07:20 UT), the magnetic field $B_{\mathrm{x}}$ component from $\mathrm{P} 2$ changed from $-5 \mathrm{nT}$ to $-15 \mathrm{nT}$ while $B_{\mathrm{Z}}$ was relatively weak between $-1 \mathrm{nT}$ and $2 \mathrm{nT}$. An earthward plasma flow $\left(V_{\mathrm{x}} \sim 210 \mathrm{~km} \mathrm{~s}^{-1}\right)$ was observed and $B_{\mathrm{Z}}$ changed from negative $(-2 \mathrm{nT})$ to positive $(3 \mathrm{nT})$ during the interval of 06:58 07:03 UT.

It is important to note that $B_{\mathrm{Z}}$ from $\mathrm{P} 2$ mainly kept negative during the interval of 07:03 07:20 UT. After 07:20 UT, $B_{\mathrm{Z}}$ varied quickly from almost $0 \mathrm{nT}$ to $-4 \mathrm{nT}$, and then back to $0 \mathrm{nT}$ at about 07:26 UT. The tailward flow $\left(V_{\mathrm{x}} \sim\right.$ $-100 \mathrm{~km} \mathrm{~s}^{-1}$ ) was observed in accompany with the quick decrease of $B_{\mathrm{z}}$. Just when $B_{\mathrm{z}}$ reached its minimum value of $-4 \mathrm{nT}$ at $\sim 07: 22 \mathrm{UT}$, ESA detected an electron bi-directional anisotropy ( $3 \mathrm{~s}$ integration on electron $3-\mathrm{D}$ velocity distribution) from $07: 22: 31 \mathrm{UT}$ to $07: 23: 19 \mathrm{UT}$ as shown in Fig. 3b. The electrons in the energy band of $150 \mathrm{eV}$ to $2 \mathrm{keV}$ were streaming around $180^{\circ}$ pitch angle, i.e. approximately earthward, while $2 \mathrm{keV}$ to $10 \mathrm{keV}$ electrons were streaming around $0^{\circ}$ pitch angle, i.e. almost tailward. Such electron streaming is a signature of reconnection due to the Hall current system, suggesting that reconnection had started near the earthward side of P2 and P2 encountered the tailward side separatrices in the Southern Hemisphere (Nagai et al., 1998b).

From 07:25 UT to 07:29 UT, P2 entered in low density lobe region (though density is not shown in this paper, one still can see this from ion spectra in Fig. 3a). We infer this as the inflow region of the reconnection site.

After 07:29 UT, an earthward flow burst was observed by P2 (Fig. 3a). The flow burst has a peak value of $285 \mathrm{~km} \mathrm{~s}^{-1}$ in $V_{\mathrm{x}}$ component and was accompanied by large amplitude magnetic field fluctuations. $\left|B_{\mathrm{X}}\right|$ decreased from about $17 \mathrm{nT}$ to $5 \mathrm{nT}$, and $B_{\mathrm{Z}}$ jumped from $0 \mathrm{nT}$ to $9 \mathrm{nT}$. At about 07:29 UT, P2 observed the electron bi-directional anisotropy signature (Fig. 3c). It is interesting that the $2 \mathrm{keV}$ to $10 \mathrm{keV}$ electrons were streaming around $180^{\circ}$ pitch angle, whereas the $150 \mathrm{eV}$ to $2 \mathrm{keV}$ electrons were streaming around $0^{\circ}$ pitch angle. The electron bi-directional anisotropy signature from 


\section{Overview}

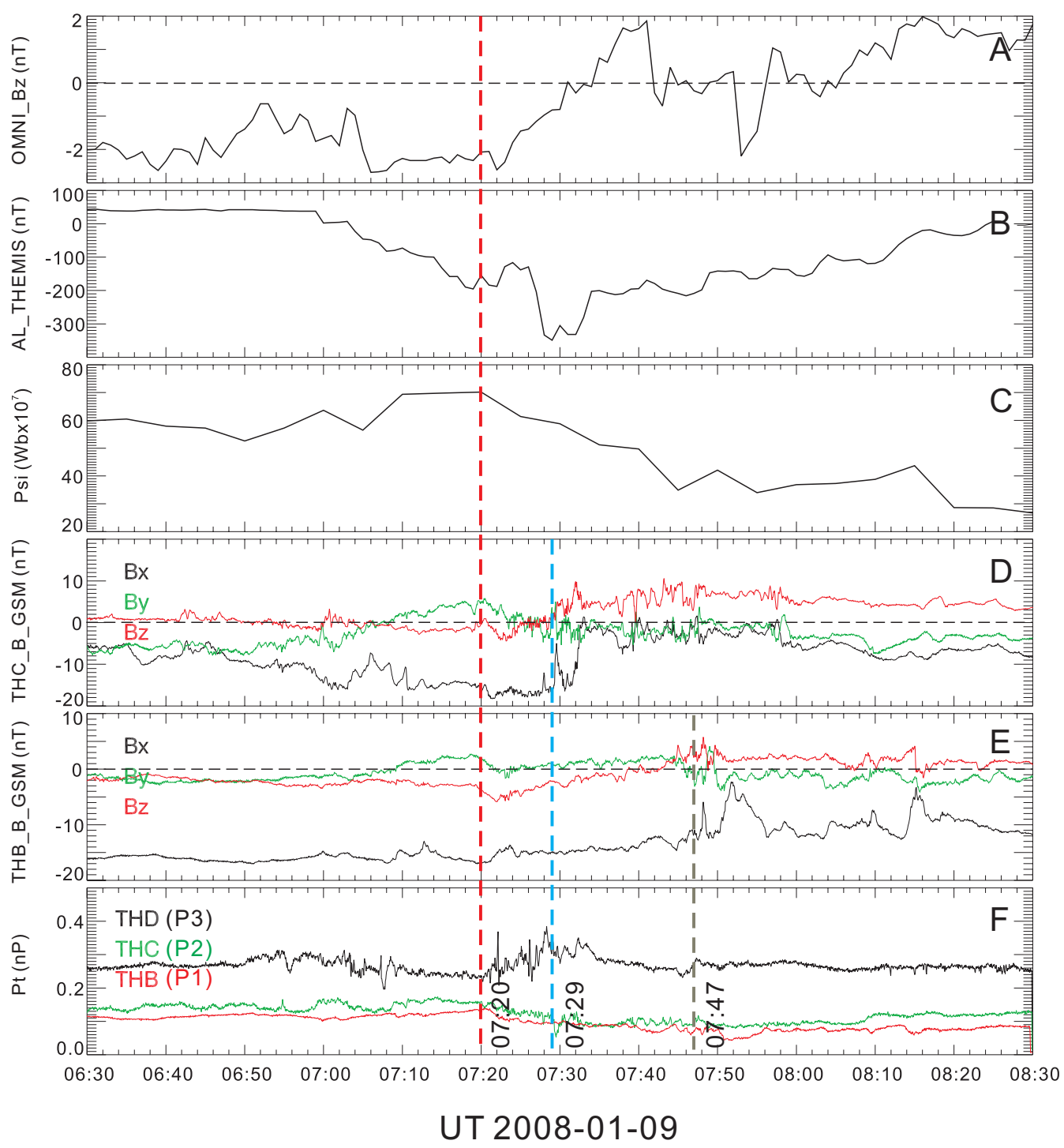

Fig. 2. Overview of the 9 January 2008 event: from top to bottom is $B_{\mathrm{Z}}$ component of IMF at 1 AU, THEMIS AL index, polar cap open flux psi, magnetic field at THC (P2), magnetic field at THB (P1) and total pressure. The red vertical dashed line stands for the start time of lobe reconnection, whereas the cyan and black vertical dashed line mark the time when THC (P2) and THB (P1) encountered the earthward side reconnection separatrices, respectively.

07:28:38 UT to 07:29:47 UT (Fig. 3c) was opposite to that from 07:22:31 UT to 07:23:19 UT (Fig. 3b).

Figure 4 shows the plasma and magnetic field observed by P1. The format of Fig. 4 is identical to that of Fig. 3. $B_{\mathrm{Z}}$ from P1 was negative $(\sim-2 \mathrm{nT})$ before 07:40 UT. A tailward flow $\left(V_{\mathrm{x}} \sim 50 \mathrm{~km} \mathrm{~s}^{-1}\right)$ was observed at 07:08 UT. From 07:19 UT to 07:22 UT, a noticeable decrease of $B_{\mathrm{Z}}$ manifested a travelling compression region (TCR) related to a tailward moving plasmoid. It is noted that the tailward flow maintained about $15 \mathrm{~min}$ from 07:08 UT to 07:23 UT. During the interval of 07:24 07:46 UT, the much low energy flux of the ions above $1 \mathrm{keV}$ indicated that P1 was located out- side the plasma sheet. From 07:22:31 UT to 07:23:07 UT and from 07:47:02 UT to 07:47:17 UT, the electron bi-directional anisotropy was observed by P1. At a magnetic reconnection site, the high energy $(>1 \mathrm{keV})$ electron jet will be observed flowing out from X-line along the separatrices, while low energy electron $(<1 \mathrm{keV})$ is expected to direct toward $\mathrm{X}$-line. This kind of electron bi-directional anisotropy was observed by P1 at both sides of the reconnection site in the Southern Hemisphere.

The tailward flow has a relatively large component in Ydirection showing an obvious deflection to westward. At the right time when P2 saw electron bi-directional anisotropy at 

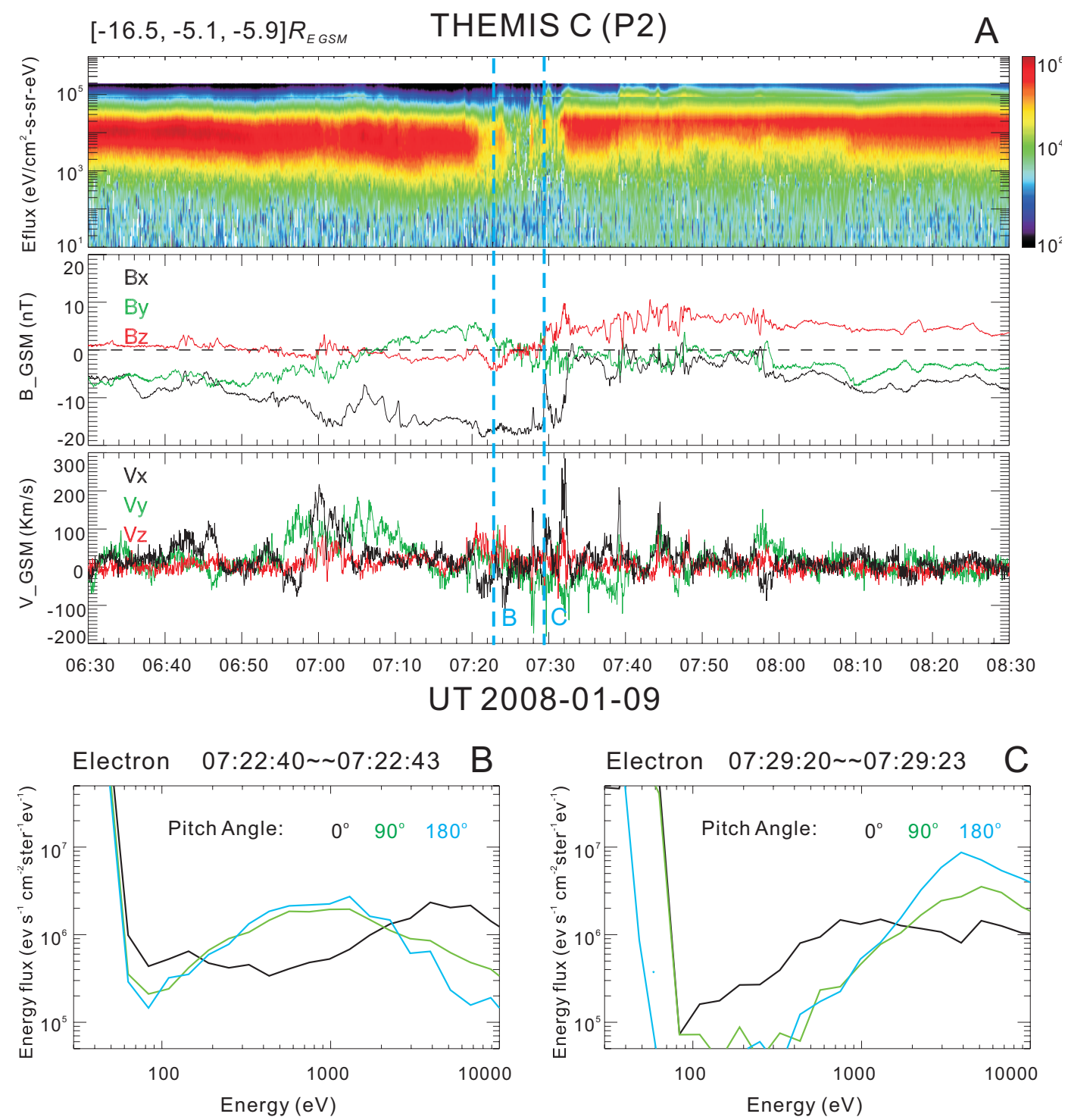

Fig. 3. Detailed observation at P2: panel (A) shows the ion spectra from $10 \mathrm{eV}$ to $50 \mathrm{keV}$, the magnetic field and the ion bulk velocity. Panels (B) and (C) give the energy flux spectra of electrons along $\left(0^{\circ}\right)$, opposite $\left(180^{\circ}\right)$ and perpendicular $\left(90^{\circ}\right)$ to the magnetic field for the times marked by the cyan vertical dashed lines in panel (A).

about 07:22 UT, P1 observed the same signature. The only difference between these two data is that the energy of flux peak value along the magnetic field $\left(0^{\circ}\right.$ pitch angle) at $\mathrm{P} 1$ was not more than $2 \mathrm{keV}$ while it was $4 \mathrm{keV}$ at $\mathrm{P} 2$, indicating the probability of existence of some energy dissipation between the two probes. Note that P1 was located far from the reconnection X-line, the data presented in Fig. $4 \mathrm{~b}$ just marked the P1 crossing of extended line of reconnection separatrices. Once P1 entered into the inflow region in the Southern Hemisphere, it shows that the magnetic field $B_{\mathrm{Z}}$ component increased smoothly from $-5 \mathrm{nT}$ to $5 \mathrm{nT}$. It took a much longer time for $\mathrm{P} 1$ to stretch over the inflow region than $\mathrm{P} 2$, since it was farther from neutral sheet to P1 than to P2. At about 07:47 UT (Fig. 4c), 18 min after P2 entered into the earthward side of the outflow region, P1 captured the same signature of electron bi-directional anisotropy as seen by P2. This electron bi-directional anisotropy was accompanied by an earthward flow burst. It is quite clear that the peak value of energy flux recorded by P1 was lower than that recorded by $\mathrm{P} 2$.

\section{Discussions}

In this paper, we have shown that a magnetic reconnection was observed simultaneously at $16.5 R_{\mathrm{E}}$ and $23.3 R_{\mathrm{E}}$. The reconnection site started to retreat tailward when IMF turned northward and psi began to drop. 

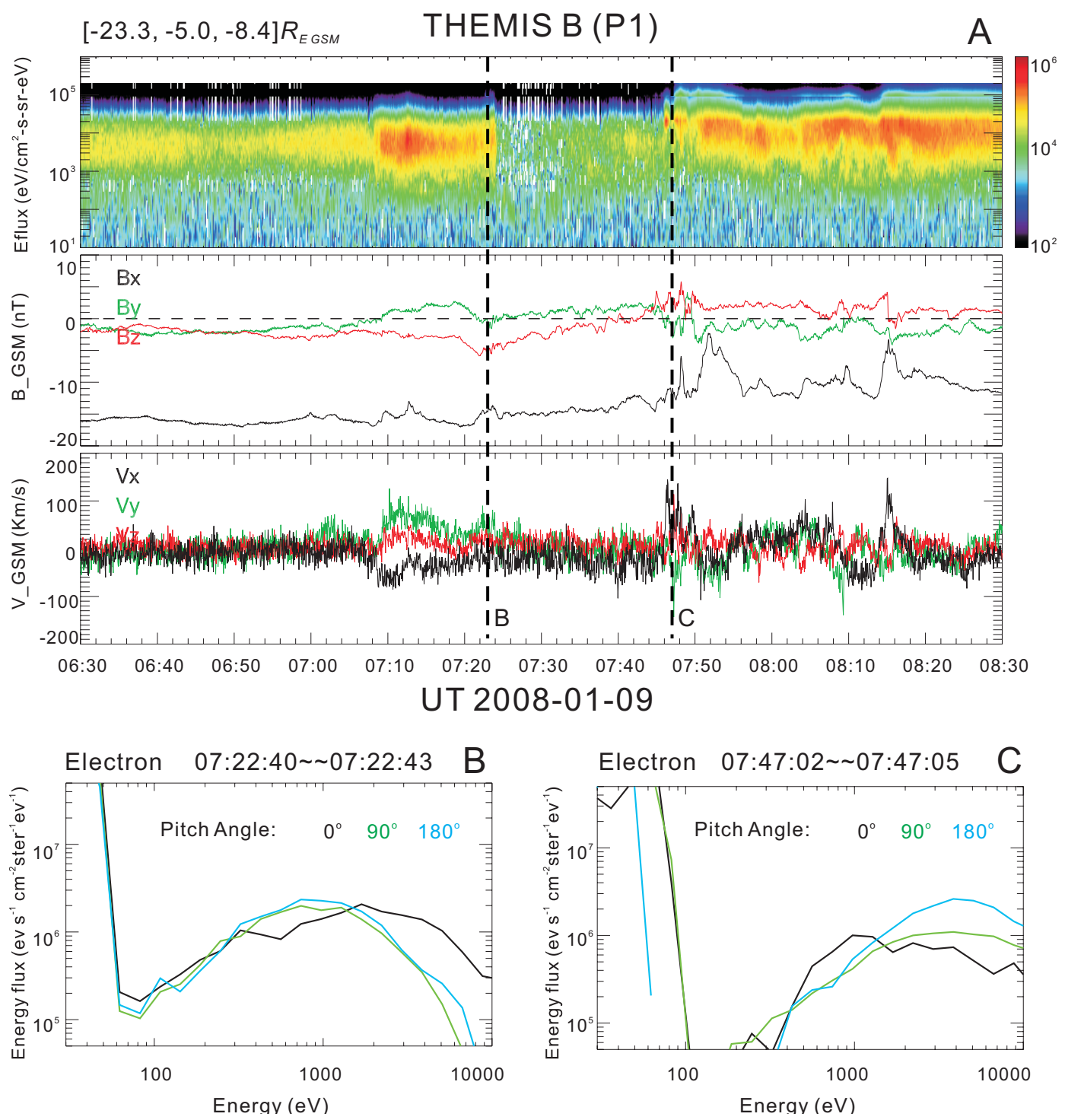

Fig. 4. Detailed observation at P1: panel (A) shows the ion spectra from $10 \mathrm{eV}$ to $50 \mathrm{keV}$, the magnetic field and the ion bulk velocity. Panels $(\mathbf{B})$ and $(\mathbf{C})$ give the energy flux spectra of electrons along $\left(0^{\circ}\right)$, opposite $\left(180^{\circ}\right)$ and perpendicular $\left(90^{\circ}\right)$ to the magnetic field for the times marked by the black vertical dashed lines in panel (A).

From the middle panel of Fig. 3a, we can see that the $B_{\mathrm{y}}$ component of the magnetic field from the $\mathrm{P} 2$ probe reached its positive peak value of $5 \mathrm{nT}$ several minutes before the $\mathrm{P} 2$ encountered the tailward side separatrices in the Southern Hemisphere (at $\sim 07: 22 \mathrm{UT}$ ). Then $B_{\mathrm{y}}$ turned to negative a few minutes after P2 crossed the earthward side separatrices in the Southern Hemisphere. It is consistent with the physical picture of the Hall current system of the reconnection ion diffusion region when $\mathrm{P} 2$ passed by a magnetic reconnection site from the tailward outflow region to the earthward outflow region. Meanwhile, P1 observed almost the same variation in the $B_{\mathrm{y}}$ component of magnetic field as $\mathrm{P} 2$ with longer duration from about 07:20 UT to 07:51 UT (Fig. 4a). Due to the large distance between $\mathrm{P} 2$ and $\mathrm{P} 1$ (almost $7 R_{\mathrm{E}}$ in the
$\mathrm{X}$-direction), we infer this Hall structure like variation in $B_{\mathrm{y}}$ component observed by $\mathrm{P} 1$ as the effect of field aligned currents along the separatrices acting to close the Hall currents mapping through the ion diffusion region far away from P1.

Both P1 and P2 observed the electron bi-directional anisotropy during the interval from 07:22:31 to 07:23:07 UT. Owen et al. (2005) suggested that the electron beams which appeared on the outermost plasma sheet boundary layer (PSBL) may be a remote observation of electrons closing the Hall current system in an ion diffusion region located far away from reconnection X-line. Our observations lead to a clear process that high energy ( $>1 \mathrm{keV}$ ) electrons left the reconnection site along separatrices at a very high speed and almost simultaneously recorded by two satellites separated 
by $7 R_{\mathrm{E}}$ along the separatrices. The only difference between the signatures at the two probes is that the energy of peak energy flux along the magnetic field line $\left(0^{\circ}\right.$ pitch angle $)$ at $\mathrm{P} 1$ probe appeared around $1.7 \mathrm{keV}$, while it appeared around $4 \mathrm{keV}$ at P2 probe. This indicates P2 detected higher energy electrons ejecting from the magnetic reconnection $\mathrm{X}$ line than that observed by P1 $7 R_{\mathrm{E}}$ far away down tail. Manapat et al. (2006) statistically studied the field-aligned electrons at the lobe/plasma sheet boundary in the mid-to-distant magnetotail and their association with reconnection. They found that in $98 \%$ of the electron beam cases the low-energy electrons are directed toward and the higher energy electrons directed away from the X-line and most detections are far away from the reconnection X-line. They also found that the observed mean field-aligned electron energies in the distant tail are lower (by about a factor of 10) than the corresponding energies observed in the near-Earth magnetotail. They suggested that this could account for the difference in the Alfvén speed in the near-Earth and the distant tail.

Before 07:20UT, P2 observed an earthward flow with bipolar signature in $B_{\mathrm{Z}}$ from negative $(-2 \mathrm{nT})$ to positive ( $3 \mathrm{nT}$ ) during the interval of 06:58 07:03 UT, which indicates the earthward passing of a flux rope. Meanwhile, the polar cap open magnetic field flux, psi, was still increasing slightly as shown in Fig. 2c. We suggest that magnetic reconnection of the closed field line had already taken place near P2 before 07:20 UT. The reconnection involved open field line in the lobe region soon after the time when IMF started to turn northward and psi started to decrease. The lobe reconnection X-line substantially evolved tailward. Ieda et al. (2001) studied brightenings in the polar ionosphere when plasmoids were observed in midtail. They found that the brightenings are closely related with the formation of plasmoids. However, they also mentioned that the brightenings do not always develop into global substorms. Russell (2000) suggested that when the IMF turns northward, reconnection at the distant neutral point ceases, the near-Earth reconnection reaches the tail lobes, releases the plasmoid and explosively reconnects tail field lines. Du et al. (2011b) also mentioned that if flux is added at the same rate on the dayside as it is removed on the nightside, the open-close field line boundary (OCB) remains stationary. When an active near Earth X-line (NEXL) rapidly reconnects lobe flux during an intense substorm, the nightside OCB expands poleward in the midnight region while open flux is quickly removed from the polar cap. Thus, the polar cap area shrinks. Our measurement directly shows the procedure that when IMF turned northward, the pre-existing near-Earth reconnection involved in the tail lobes and the psi dropped. Soon after the reconnection involved into tail lobes, the magnetic field of the plasmoid decoupled from the ionosphere, which was followed by the tailward retreat of the near-Earth X-line.

After 07:20UT, P3 in the near-Earth plasma sheet observed that the total pressure increased rapidly with large amplitude fluctuations in the $\mathrm{Pi} 2$ frequency range. On the other hand, P1 and P2 observed that total pressure decreased at the same time in the mid-tail region. Recently Xing et al. (2010) statistically analysed the plasma sheet pressure evolution related to substorms. Their results showed that for a majority of substorm cases, the plasma pressure enhances after the onset at the earthward side of $-12 R_{\mathrm{E}}$ while the plasma pressure beyond $-16 R_{\mathrm{E}}$ shows a remarkable decrease near onset. Their findings are consistent with whats in this case. It is worth while to mention again that after 07:29 UT the total pressure stopped the decrease at P2 probe when P2 entered into the earthward-side outflow region, while the total pressure continued to decrease until 07:47 UT when P1 entered the earthward-side outflow region as well. We suggest that the force balance between the pressure gradient and magnetic field tension force in the $\mathrm{X}$ direction was broken when reconnection involved lobe field line, the earthward-side outflow region of the lobe reconnection maintained a relatively higher pressure than that at tailward side. This pressure difference might drive the lobe reconnection X-line further down tail in the absence of magnetic field tension force.

To estimate the retreat speed of the reconnection site observed by $\mathrm{P} 1$ and $\mathrm{P} 2$, we first decide the time interval between X-line crossing of P2 and P1. We take 07:26 UT as the $\mathrm{X}$-line crossing time when $\mathrm{P} 2$ observed the northward turning of $B_{\mathrm{Z}}$, and take 07:43 UT as the X-line crossing time of P1. The distance between the two satellites of P1 and P2 in the $\mathrm{X}$ direction was about $6.8 R_{\mathrm{E}}$. Then we can get the retreat speed of $X$-line to be about $42 \mathrm{~km} \mathrm{~s}^{-1}$. This speed is roughly the same as the retreat speed of magnetic field dipolarization ( $35 \mathrm{~km} \mathrm{~s}^{-1}$ ) observed by Baumjohann et al. (1999) but is rather lower than the $\mathrm{X}$-line retreat speed observed by Nagata et al. (2006).

\section{Summary}

The 9 January 2008 event described above demonstrates that during the substorm expansion phase, reconnection in closed field line had taken place somewhere in the mid-tail. When IMF turned northward, the reconnection in the mid-tail then involved tail lobe open field line and polar cap open magnetic field flux psi decreased substantially and the reconnection X-line retreated gradually tailward. Although this work provides insight into how the reconnection X-line proceeds, further detailed study is needed to get better understanding of substorm related magnetotail dynamics.

Acknowledgements. This work is supported by NSFC grants 40890163, 40731056, 41174122, 40974095, 40904043, 2011CB811404, 2012CB825604 and 41011120250. We acknowledge NASA contract NAS5-02099 and V. Angelopoulos for the use of data from the THEMIS Mission. Specifically: D. Larson and R. P. Lin for the use of SST data. We thank George Parks for the helpful discussion and POLAR UVI data.

Topical Editor R. Nakamura thanks two anonymous referees for their help in evaluating this paper. 


\section{References}

Alexeev, I. V., Owen, C. J., Fazakerley, A. N., Runov, A., Dewhurst, J. P., Balogh, A., Rème, H., Klecker, B., and Kistler, L.: Cluster observations of currents in the plasma sheet during reconnection, Geophys. Res. Lett., 32, L03101, doi:10.1029/2004GL021420, 2005.

Angelopoulos, V., Mitchell, D. G., McEntire, R. W., Williams, D. J., Lui, A. T. Y., Krimigis, S. M., Decker, R. B., Christon, S. P., Kokubun, S., Yamamoto, T., Saito, Y., Mukai, T., Mozer, F. S., Tsuruda, K., Reeves, G. D., Hughes, W. J., Friis-Christensen, E., and Troshichev, O.: Tailward propagation of magnetotail acceleration centers: Relationship to substorm current wedge, J. Geophys. Res., 101, 24599-24619, 1996.

Angelopoulos, V., McFadden, J. P., Larson, D., Carlson, C. W., Mende, S. B., Frey, H., Phan, T., Sibeck, D. G., Glassmeier, K. H., Auster, U., Donovan, E., Mann, I. R., Rae, I. J., Russell, C. T., Runov, A., Zhou, X. Z., and Kepko, L.: Tail reconnection triggering substorm onset, Science, 321, 931-935, doi:10.1126/science.1160495, 2008.

Auster, H. U., Glassmeier, K. H., Magnes, W., Aydogar, O., Baumjohann, W., Constantinescu, D., Fischer, D., Fornacon, K. H., Georgescu, E., Harvey, P., Hillenmaier, O., Kroth, R., Ludlam, M., Narita, Y., Nakamura, R., Okrafka, K., Plaschke, F., Richter, I., Schwarzl, H., Stoll, B., Valavanoglou, A., and Wiedemann, M.: The THEMIS fluxgate magnetometer, Space Sci. Rev., 141, 235-264, 2008.

Baker, D. N., Pulkkinen, T. I., Angelopoulos, V., Baumjohann, W., and McPherron, R. L.: The neutral line model of substorms: Past results and present view, J. Geophys. Res., 101, 12975-13010, doi:10.1029/95JA03753, 1996.

Baker, D. N., Peterson, W. K., Eriksson, S., Li, X., Blake, J. B., Burch, J. L., Daly, P. W., Dunlop, M. W., Korth, A., Donovan, E., Friedel, R., Fritz, T. A., Frey, H. U., Mende, S. B., Roeder, J., and Singer, H. J.: Timing of magnetic reconnection initiation during a global magnetospheric substorm onset, Geophys. Res. Lett., 29, 2190, doi:10.1029/2002GL015539, 2002.

Baumjohann, W., Paschmann, G., Sckopke, N., Cattell, C. A., and Carlson, C. W.: Average ion moments in the plasma sheet boundary layer, J. Geophys. Res., 93, 11507-11520, 1988.

Baumjohann, W., Paschmann, G., and Cattell, C. A.: Average plasma properties in the central plasma sheet, J. Geophys. Res., 94, 6597-6606, 1989.

Baumjohann, W., Paschmann, G., and Lühr, H.: Characteristics of high-speed ion flows in the plasma sheet, J. Geophys. Res., 95, 3801-3809, 1990.

Baumjohann, W., Paschmann, G., Nagai, T., and Lühr, H.: Superposed epoch analysis of the substorm plasma sheet, J. Geophys. Res., 96, 11605-11608, 1991.

Baumjohann, W., Hesse, M., Kokubun, S., Mukai, T., Nagai, T., and Petrukovich, A. A.: Substorm dipolarization and recovery, J. Geophys. Res., 104, 24995-25000, 1999.

Cao, X., Pu, Z. Y., Zhang, H., Mishin, V. M., Ma, Z. W., Dunlop, M. W., Fu, S. Y., Xie, L., Xiao, C. J., Wang, X. G., Zong, Q. G., Liu, Z. X., Kubyshkina, M. V., Pulkkinen, T. I., Frey, H. U., Korth, A., Fraenz, M., Lucek, E., Carr, C. M., Reme, H., Dandouras, I., Fazakerley, A. N., Reeves, G. D., Friedel, R., Glassmeier, K. H., and Escoubet, C. P.: Multispacecraft and ground-based observations of substorm timing and activations: Two case studies, J. Geophys. Res., 113, A07S25, doi:10.1029/2007JA012761, 2008.
Cattell, C. A. and Mozer, F. S.: Substorm electric fields in the Earth's magnetotail, in: Magnetic Reconnection in Space and Laboratory Plasmas, Geophys. Monogr. Ser., vol. 30, edited by: Hones Jr., E. W., pp. 208-215, AGU, Washington, D.C., 1984.

Du, A. M., Nakamura, R., Zhang, T. L., Panov, E. V., Baumjohann, W., Luo, H., Xu, W. Y., Lu, Q. M., Volwerk, M., Retino, A., Zieger, B., Angelopoulos, V., Glassmeier, K. H., McFadden, J. P., and Larson, D.: Fast tailward flows in the plasma sheet boundary layer during a substorm on 9 March 2008: THEMIS observations, J. Geophys. Res., 116, A03216, doi:10.1029/2010JA015969, 2011a.

Du, A. M., Sun, W., Tsurutani, B. T., Boroyev, R. N., and Moiseyev, A. V.: Observations of dawn-dusk aligned polar cap aurora during the substorms of January 21, 2005, Planet. Space Sci., 59, 1551-1558, 2011b.

Dungey, J. W.: Interplanetary magnetic field and the auroral zones, Phys Rev. Lett., 6, 47-48, 1961.

Forbes, T. G., Hones, E. W., Bame, S. J., Asbridge, J. R., Paschmann, G., Sckopke, N., and Russell, C. T.: Evidence for the tailward retreat of a magnetic neutral line in the magnetotail during substorm recovery, Geophys. Res. Lett., 8, 261-264, 1981.

Fujimoto, M., Nakamura, M. S., Shinohara, I., Nagai, T., Mukai, T., Saito, Y., Yamamoto, T., and Kokubun, S.: Observations of earthward streaming electrons at the trailing boundary of a plasmoid, Geophys. Res. Lett., 24, 2893-2896, 1997.

Fujimoto, M., Nagai, T., Yokokawa, N., Yamade, Y., Mukai, T., Saito, Y., and Kokubun, S.: Tailward electrons at the lobe-plasma sheet interface detected upon dipolarizations, J. Geophys. Res., 106, 21255-21262, 2001.

Hones Jr., H. W.: The magnetotail: Its generation and dissipation, in Physics of Solar Planetary Environments, edited by: Williams, D. J., pp. 558-571, AGU, Washington, D.C., 1976.

Hones Jr., E. W., Asbridge, J. R., Bame, S. J., and Singer, S.: Substorm variations of the magnetotail plasma sheet from XSM $\approx-6 R_{\mathrm{E}}$ to $\mathrm{XSM} \approx-60 R_{\mathrm{E}}$, J. Geophys. Res., 78, 109-132, doi:10.1029/JA078i001p00109, 1973.

Hoshino, M., Mukai, T., Terasawa, T., and Shinohara, I.: Suprathermal electron acceleration in magnetic reconnection, J. Geophys. Res., 106, 25979-25997, 2001.

Ieda, A., Machida, S., Mukai, T., Saito, Y., Yamamoto, T., Nishida, A., Terasawa, T., and Kokubun, S.: Statistical analysis of the plasmoid evolution with Geotail observations, J. Geophys. Res., 103, 4453-4465, 1998.

Ieda, A., Fairfield, D., Mukai, T., Saito, Y., Kokubun, S., Liou, K., Meng, C.-I., Parks, G., and Brittnacher, M.: Plasmoid ejection and auroral brightenings, J. Geophys. Res., 106, 3845-3857, 2001.

Lu, Q. M., Huang, C., Xie, J. L., Wang, R. S., Wu, M. Y., Vaivads, A., and Wang, S.: Features of separatrix regions in magnetic reconnection: Comparison of 2-D particle-in-cell simulations and Cluster observations, J. Geophys. Res., 115, A11208, doi:10.1029/2010JA015713, 2010.

Manapat, M., Øieroset, M., Phan, T. D., Lin, R. P., and Fujimoto, M.: Field-aligned electrons at the lobe/plasma sheet boundary in the mid-to-distant magnetotail and their association with reconnection, Geophys. Res. Lett., 33, L05101, doi:10.1029/2005GL024971, 2006.

McFadden, J. P., Carlson, C. W., Larson, D., Ludlam, M., Abiad, 
R., Elliott, B., Turin, P., Marckwordt, M., and Angelopoulos, V.: The THEMIS ESA plasma instrument and in-flight calibration, Space Sci. Rev., 141, 277-302, 2008.

McPherron, R. L., Russell, C. T., and Aubry, M. P.: Satellite studies of magnetospheric substorms on August 15, 1968: 9. Phenomenological model for substorms, J. Geophys. Res., 78, 3133 3149, 1973.

Mishin, V. M., Saifudinova, T., Bazarzhapov, A., Russell, C. T., Baumjohann, W., Nakamura, R., and Kubyshkina, M.: Two distinct substorm onsets, J. Geophys. Res., 828, 13105-13118, doi:10.1029/2000JA900152, 2001.

Miyashita, Y., Kamide, Y., Machida, S., Liou, L., Mukai, T., Saito, Y., Ieda, A., Meng, C.-I., and Parks, G. K.: Difference in magnetotail variations between intense and weak substorms, J. Geophys. Res., 109, A11205, doi:10.1029/2004JA010588, 2004.

Miyashita, Y., Miyoshi, Y., Matsumoto, Y., Ieda, A., Kamide, Y., Nose, M., Machida, S., Hayakawa, H., McEntire, R. W., Christon, S. P., Evans, D. S., and Troshichev, Q. A.: Geotail observations of signatures in the near-Earth magnetotail for the extremely intense substorms of the 30 October 2003 storm, J. Geophys. Res., 110, A09S25, doi:10.1029/2005JA011070, 2005.

Miyashita, Y., Machida, S., Kamide, Y., Nagata, D., Liou, K., Fujimoto, M., Ieda, A., Saito, M. H., Russell, C. T., Christon, S. P., Nose, M., Frey, H. U., Shinohara, I., Mukai, T., Saito, Y., and Hayakawa, H.: A state-of-the-art picture of substorm associated evolution of the near-Earth magnetotail obtained from superposed epoch analysis, J. Geophys. Res., 114, A01211, doi:10.1029/2008JA013225, 2009.

Nagai, T.: Magnetic reconnection in the magnetotail: Review of the Japanese contribution with the spacecraft Geotail, in: Frontiers of Magnetospheric Plasma Physics, COSPAR Colloq. Ser., vol. 16, edited by: Hoshino, M., Omura, Y., and Lanzerotti, L., pp. 87-99, Elsevier, New York, 2005.

Nagai, T.: Location of magnetic reconnection in the magnetotail, Space Sci. Rev., 122, 39-54, doi:10.1007/s11214-006-6216-4, 2006.

Nagai, T. and Machida, S.: Magnetic reconnection in the near-Earth magnetotail, in: New Perspectives on the Earth's Magnetotail, Geophys. Monogr. Ser., vol. 105, edited by: Nishida, A., Baker, D. N., and Cowley, S. W. H., pp. 211-224, AGU, Washington, D.C., 1998.

Nagai, T., Fujimoto, M., Saito, Y., Machida, S., Terasawa, T., Nakamura, R., Yamamoto, T., Mukai, T., Nishida, A., and Kokubun, S.: Structure and dynamics of magnetic reconnection for substorm onsets with Geotail observations, J. Geophys. Res., 103, 4419-4440, 1998.

Nagai, T., Shinohara, I., Fujimoto, M., Hoshino, M., Saito, Y., Machida, S., and Mukai, T.: Geotail observations of the Hall current system: Evidence of magnetic reconnection in the magnetotail, J. Geophys. Res., 106, 25929-25949, 2001.

Nagai, T., Fujimoto, M., Nakamura, R., Baumjohann, W., Ieda, A., Shinohara, I., Machida, S., Saito, Y., and Mukai, T.: Solar wind control of the radial distance of the magnetic reconnection site in the magnetotail, J. Geophys. Res., 110, A09208, doi:10.1029/2005JA011207, 2005.
Nagata, D., Machida, S., Ohtani, S., Mende, S. B., Saito, Y., and Mukai, T.: Remote sensing of a near-Earth neutral line during the 5 October 2000 substorm, Ann. Geophys., 24, 3497-3505, doi:10.5194/angeo-24-3497-2006, 2006.

Øieroset, M., Phan, T. D., Fujimoto, M., Lin, R. P., and Lepping, R. P.: In situ detection of collisionless reconnection in the Earth's magnetotail, Nature, 412, 414-417, 2001.

Owen, C. J., Slavin, J. A., Fazakerley, A. N., Dunlop, M. W., and Balogh, A.: Cluster electron observations of the separatrix layer during travelling compression regions, Geophys. Res. Lett., 32, L03104, doi:10.1029/2004GL021767, 2005.

Runov, A., Nakamura, R., Baumjohann, W., Zhang, T. L., Volwerk, M., Eichelberger, H.-U., and Balogh, A.: Cluster observation of a bifurcated current sheet, Geophys. Res. Lett., 30, 1036, doi:10.1029/2002GL016136, 2003a.

Runov, A., Nakamura, R., Baumjohann, W., Treumann, R. A., Zhang, T. L., Volwerk, M., Voros, Z., Balogh, A., Glassmeier, K. H., Klecker, B., Reme, H., and Kistler, L.: Current sheet structure near magnetic X-line observed by Cluster, Geophys. Res. Lett., 30, 1579, doi:10.1029/2002GL016730, 2003 b.

Russell, C. T.: How northward turnings of the IMF can lead to substorm expansion onsets, Geophys. Res. Lett., 27, 3257-3259, 2000.

Slavin, J. A., Tanskanen, E. I., Hesse, M., Owen, C. J., Dunlop, M. W., Imber, S., Lucek, E. A., Balogh, A., and Glassmeier, K.-H.: Cluster observations of travelling compression regions in the near-tail, J. Geophys. Res., 110, A06207, doi:10.1029/2004JA010878, 2005.

Torr, M. R., Torr, D. G., Zukic, M., Johnson, R. B., Ajello, J., Banks, P., Clark, K., Cole, K., Keffer, C., Parks, G., Tsurutani, B., and Spann, J.: A far ultraviolet imager for the international solar terrestrial physics mission, Space Sci. Rev., 71, 329-383, 1995.

Ueno, G., Machida, S., Mukai, T., Saito, Y., and Nishida, A.: Distribution of X-type magnetic neutral lines in the magnetotail with Geotail observations, Geophys. Res. Lett., 26, 3341-3344, 1999.

Wang, Q. J., Du, A. M., Zhao, X. D., Luo, H., and Xu, W. Y.: Manifestation of the AE index in substorms on August 6, 1998, Chinese J. Geophys, 52, 2943-2950, 2009.

Wang, R. S., Lu, Q. M., Huang, C., and Wang, S.: Multispacecraft observation of electron pitch angle distributions in magnetotail reconnection, J. Geophys. Res., 115, A01209, doi:10.1029/2009JA014553, 2010a.

Wang, R. S., Lu, Q. M., Li, X., Huang, C., and Wang, S.: Observations of energetic electrons up to $200 \mathrm{keV}$ associated with a secondary island near the center of an ion diffusion region: A Cluster case study, J. Geophys. Res., 115, A11201, doi:10.1029/2010JA015473, 2010b.

Xing, X., Lyons, L. R., Angelopoulos, V., Larson, D., Carlson, C., Runov, A., and Auster, U.: Plasma sheet pressure evolution related to substorms, J. Geophys. Res., 115, A01212, doi:10.1029/2009JA014315, 2010. 